\title{
Designing a Poultry Barn: A Collaborative Design Approach Using Virtual Reality
}

\author{
K.Pradeep ${ }^{*}$ and R.Selvabharathi ${ }^{1}$ \\ \{kpp.psgtech@gmail.com ${ }^{1 *}$, selvabharathi2801@ gmail.com $\left.{ }^{1}\right\}$ \\ Assistant Professor, Department of Production Engineering, PSG College of Technology \\ Coimbatore, India ${ }^{1 *}$., Senior Project Manager, Department of Production Engineering, PSG College \\ of Technology, Coimbatore, India.
}

\begin{abstract}
Visualizing a new design in Virtual Reality (VR) is now a part of product development pipeline in several industries. Several researchers have demonstrated attaining higher level of immersion by creating photoreal virtual environments and by using advanced devices which are now available in the market to get higher level of tracking accuracy and higher degree of interaction. In this work, we have explored the possibility of using the VR technology during the design phase with a multidisciplinary approach. Through this work, we have demonstrated that a regular Head Mounted Display (HMD) which lacks several features when compared to the pricier ones is sufficient for product development and visualization. Using VR, we even managed to design the building which will house the product that we developed. We have chosen a poultry farm that breeds chickens for this study and solved their problem of repetitive manual work by designing an automated feeding system. We manged to all this with the same virtual environment that we have developed for the purpose of this study.
\end{abstract}

Keywords: Product development, virtual reality, collaboration and interdisciplinary.

\section{Introduction}

In poultry barns, large number of chickens are raised to be later sold to either the local market or to food processing centres [1]. The chickens are providing with sufficient food and water as per the local government regulations [2] and [3]. On an average, it takes about 12 weeks for a chicken to reach its standard weight which is about $2.5 \mathrm{KG}$ [4]. After proper inspections, the chicken is transported to the food processing industry [5], [6] and [7]. In several countries, automation is done for feeding the chickens [8], [9], [10], [11], [12] and [13]. But such systems are almost non-existent in many developing and underdeveloped nations [14]. This is mainly due to the cost and technical expertise that is needed to operate such system. Hence there is a needed in developing a cost-effective automatic feeding system for small barn owners. Poultry barns are designed to both keep the chicken inside the barn and to protect them from natural predicators which are habitants in the geographics location where the barn is located. Safety of barn workers should also be considered while building a barn. Having proper ventilation facility with sufficient lights and maintain proper temperature is necessary for the growth of the barn gown chickens [15].

Traditional approach in New Product Development (NPD) involves customer need identification, concept generation, concept evaluation, design generation, design evaluation, fabrication and documentation [16]. The same is illustrated in Fig.1. With the advancement in 
digital technologies, we are now employing new digital technologies while developing products. Technologies such as Cloud [17], [18] and [19], Deep Learning [20], [21], [22] and [23], Virtual Reality [24], [25], [26], [27] and [28], Augmented Reality [29], [30], [31], [32] and [33] and Mixed reality [34], [35], [36], [37] and [38] are widely used at different stages of product development. Customer data from various sources especially those from the internet [39], [40], [41], [42], [43], [44] and [45] are extensively used in NPD. In earlier days, while developing products to meet the needs of a single or a small group of customers was less feasible from the cost perspective [46]. This is no longer acceptable as the customer preferences have now become very diverse [47] and [48]. Customers prefer very high degree of customization in their products and services that they pay for [49]. Hence, organizations are looking at new technologies to cut cost at different stages of product development to accommodate greater degree of product customization. It is worth noting that most of the costs in NPD is associated with the design phase. This cost can be reduced by effectively utilizing time and resources during the designing of products with the help of the above listed technologies [50]. Digital technologies have created an era of stronger interdisciplinary collaborations. Proper collaboration of multiple teams from both within and outside of the organization while developing new products will lead to innovative and high value products [51], [52], [53], [54], [55], [56] and [57].

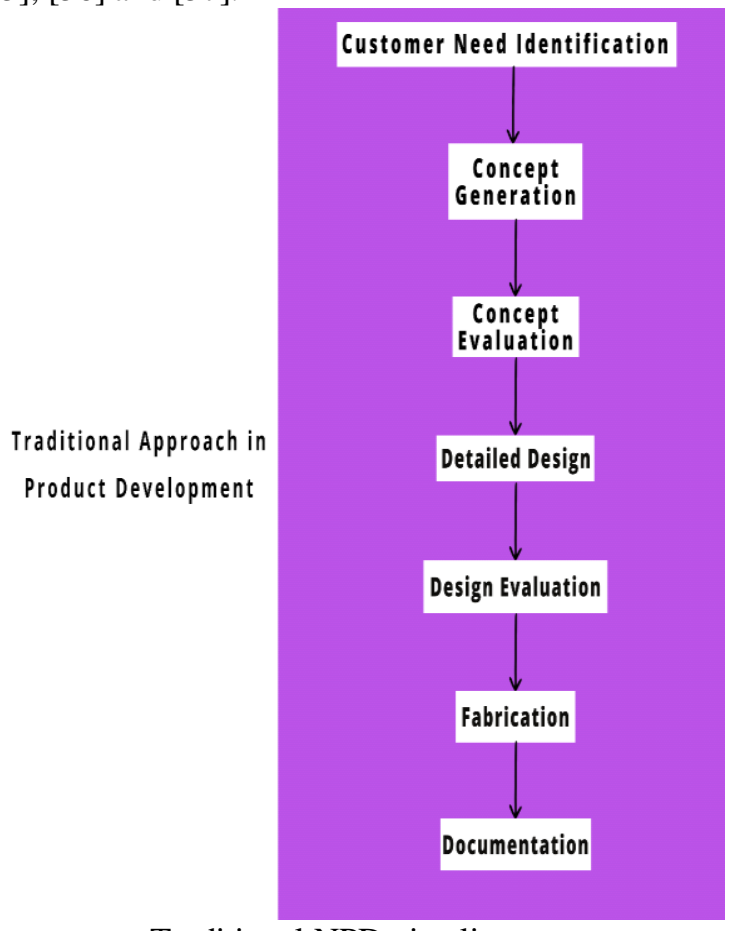

Traditional NPD pipe line

Digital technologies enable Collaborative Product Development (CPD). CPD offers significant benefits over the traditional approach such as faster development time, faster redesign, and higher possibility of early product launch [58]. CPD eliminates any domain specific biases that would arise while evaluating the large system design. This not only gives different perspectives while developing new products, but it also adds value to the design by identifying earlier unknown issues and providing an interdisciplinary solution. 
In recent years, VR technology is being used to enable Collaborative Product Development (CPD). Industries are getting the benefits of virtual prototyping which is a product of VR that eliminates the costs associated with making a physical prototype [59], [60], [61] and [62]. In VR, more than one person can be present in the virtual world. This makes evaluation of concepts and designs with interdisciplinary teams possible [63].

\section{Method}

For this work, we have collaborated with a local poultry barn owner who wishes to automate his barn. To begin with, we collected data from the existing barn and generated concepts that would replace it. We have used commercial CAD software to develop 3D models of the existing and the proposed barn and the automated system. We then converted the models to VRML file standard to use in the virtual environment built using the VR technology. We used a commercial VR application development software which runs on python to develop the VR environment. Sony Head Mounted Display (HMD) was used for viewing into the VR environment. The HMD comes with limited capabilities and does not have position and orientation trackers. Nevertheless, we chose to use it to minimize the costs associated with VR technology. With VR, it is now possible to merge multiple stages in the NPD (concept evaluation, detailed design, design evaluation) and thus reducing time needed for finalizing the design (Fig. 2). Before we developed the VR environment, we created a detailed storyboard to design the User Interface (UI), to manage event triggers and to determine what virtual objects must be placed in the field of view of the user. To improve realism, we have added models of the barn chickens to the VR environment. The chicken is passively animated with sound and its motion is controlled by a random number algorithm.

\section{Developing the Virtual World}

\section{Modeling and Simulating the Existing System in VR}

Most poultry farms in both developing and underdeveloped nations use manual labor to feed and monitor the animals at the barns. In several instances, it is the owner of the barn that takes up the responsibility of refilling the feeding troughs regularly. To understand the challenges, the poultry barn worker faces, we have recreated and visualized the existing barn in VR. We did so to uncover design and usability problems that are not indicted by the end user. 


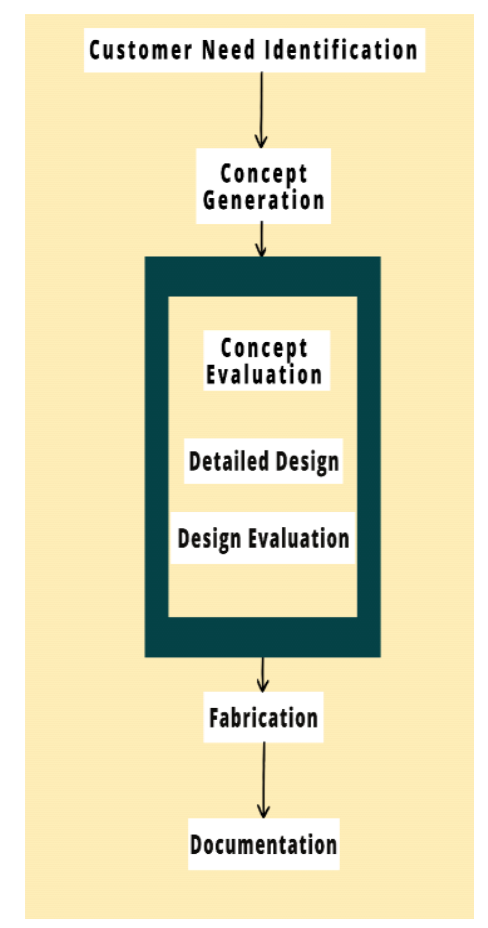

\section{NPD Pipeline with Virtual Reality technology}

We created the 3D models of the feeder troughs (Fig.3) and gave it color to make it look more realistic. We positioned them as how they are placed in the existing farm (Fig.4). We even added a virtual human character which would be controlled by the user using the keyboard. We built the VR system in a way that when the user puts on the HMD, he would see through the eyes of this virtual human character. We have created provisions for more users to view the VR environment from a third person perspective which mirrors the actions of the user with HMD (Fig.5).

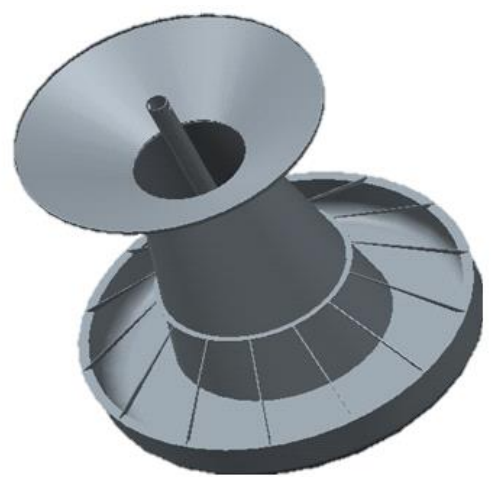

Recreating the existing feeder trough in $\mathrm{CAD}$ 

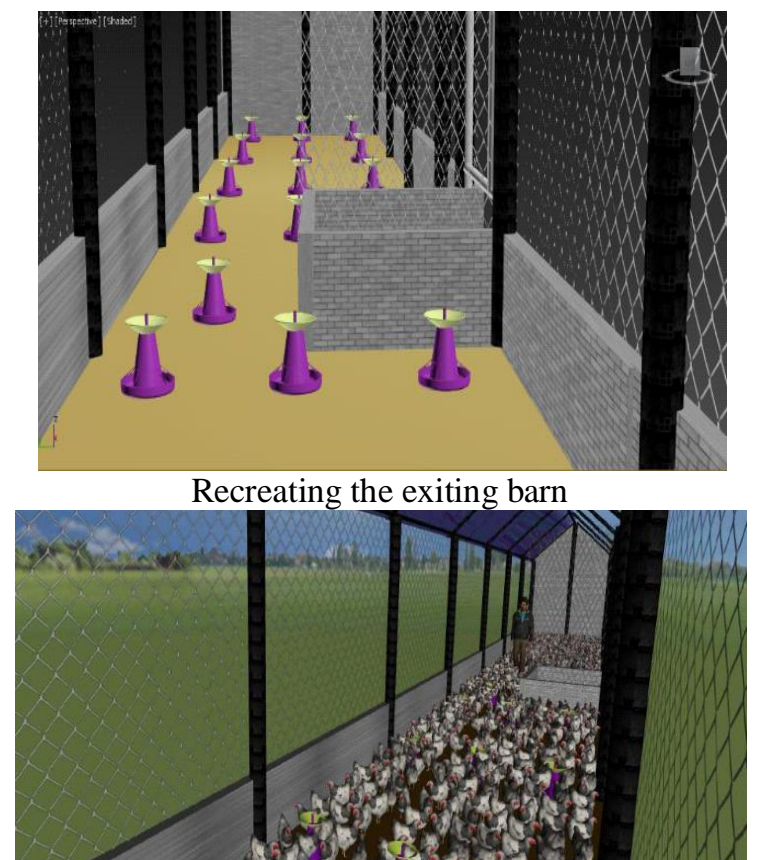

Viewing the interior of the existing poultry barn in VR

\section{Modeling and Simulating the Proposed Design in VR}

The automatic feeding system is utilized in barns across the globe. The system consists of a big hopper which is usually placed in separate location outside the barn. The feed is sent to the barn though the hopper. Feed is then moved from the hopper to the feeding troughs through the small pipes which connects the trough to the hopper. We evaluated the design of the feeding system, placement of feeding roughs and the barn itself in the VR environment (Fig.7). After and elaborate visual inspection and redesigns, we were able to freeze the design that works in engineering terms and something that the end user likes (Fig.8). We had to use interdisciplinary approach in the design process.

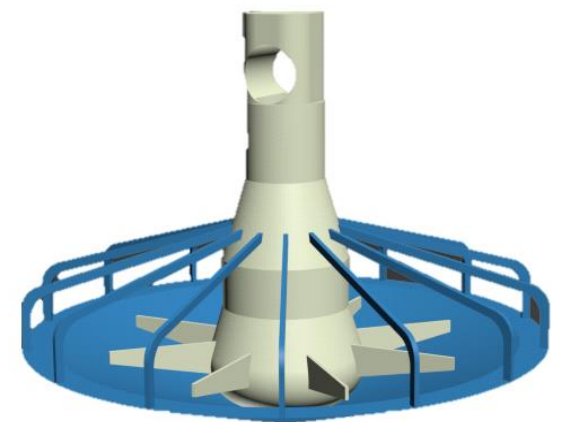

3D Model of the feeding trough suggested for use in the proposed design 


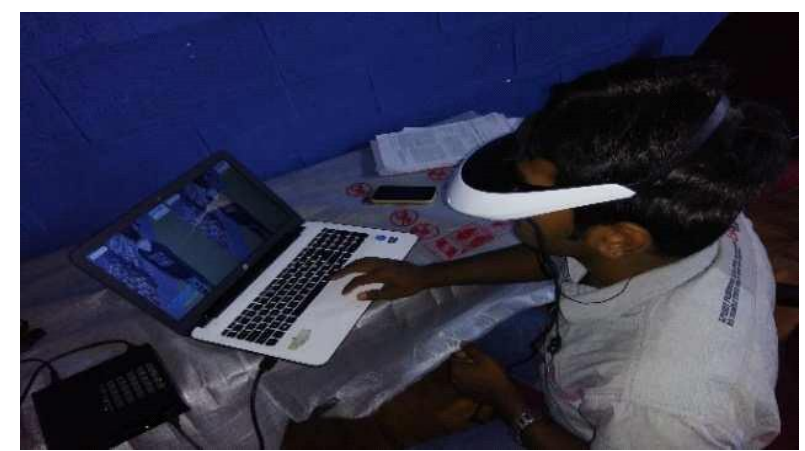

Viewing the interior of the proposed poultry barn in VR

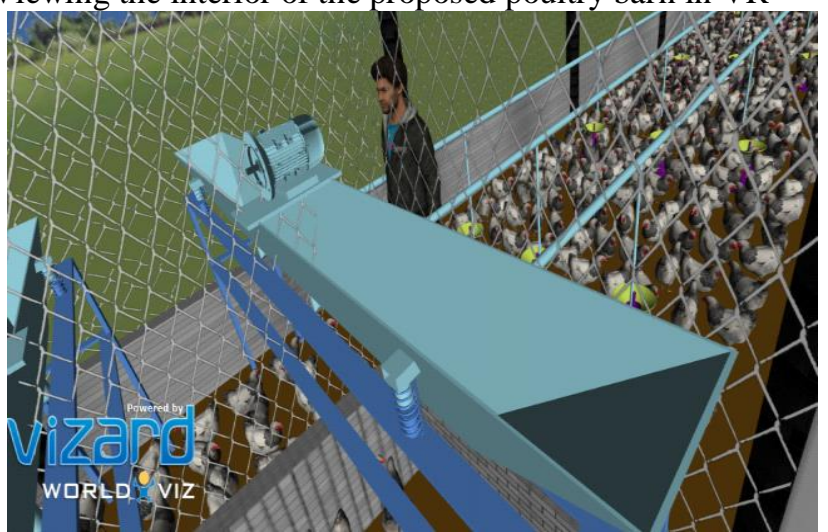

$3^{\text {rd }}$ Person view of the VR environment with the final design

\section{Conclusion}

Through this work, we have demonstrated that product can be collaboratively developed on systems built on the Virtual Reality technology. We have utilized an HMD with lesser frame rate, no position, and no orientation trackers. The virtual environment that we have built offers lesser immersion, but we were able to run it without many difficulties even on a laptop which offers lesser computation capabilities when compared to the workstations which are normally used for this purpose. Having low framerate, and less immersion did not impact the objectives. Hence, we encourage product developers to utilize low-cost HMDs for design visualization. Which will save a significant amount of money that would otherwise be spent on purchasing high performance trackers, HMD's with higher frame rate and How a product would behave in its work environment well before finalising the design during the design phase of the work in this work we were also able to see both the products there's a feeder system and the born in which the product would be built into though this work through this work we have demonstrated that we can develop and evaluate multiple products which should be developed collaboratively and by interdisciplinary teams. Such an interdisciplinary system will promote entrepreneurship as it will make it a little bit easy for new entrepreneurs to plan their workspace and office buildings all in a single environment. With the ability of cloud, 5G and AI technologies one can even simulate the productivity of such workspace in real time. 
This will provide the entrepreneurs plan the capability to customize their workspace, plan for facilities and estimate cost and productivity all in a single virtual world.

\section{Acknowledgment}

We thank the institution management for providing moral encouragement and for providing the funding to carry out this work.

\section{References}

[1] Mahendra Kumar Padhi, "Importance of Indigenous Breeds of Chicken for Rural Economy and Their Improvements for Higher Production Performance", Scientifica, vol. 2016, April 2016.

[2] "The Caged Chicken or the Free-Range Egg? The Regulatory and Market Dynamics of Layer-Hen Welfare in the UK, Australia and the USA", Journal of Agricultural and Environmental Ethics, vol. 30, pp. 783-808, November 2017.

[3] Christine Parker, Gyorgy Scrinis, Rachel Carey and Laura Boehm, “A Public Appetite for Poultry Welfare Regulation Reform: Why Higher Welfare Labelling is not Enough", Alternative Law Journal, vol. 43, no. 4, pp. 238-243, November 2018.

[4] Gyorgy Scrinis, Christine Parker and Rachel Carey, Massimiliano Petracci and Cécile Berri, Poultry Quality Evaluation: Quality Attributes and Consumer Values, 1st Edition, Woodhead Publishing, 2017, Pages 51-75.

[5] Aziz, Nurhanna Abdul and Mohd Fauzi Bin Othman, "Binary Classification using SVM for Sick and Healthy Chicken Based on Chicken's Excrement Image", Pertanika Journal of Science \& Technology, vol. 25, pp. 315-324, 2017.

[6] G. Douglas Inglis, Nahal Ramezani, Eduardo N. Taboada, Valerie F. Boras, and Richard R. E. Uwiera, "Analysis of Campylobacter jejuni Subtype Distribution in the Chicken Broiler Production Continuum: A Longitudinal Examination to Identify Primary Contamination Points", Applied and Environmental Microbiology, vol. 87, no. 3, January 2021.

[7] S. N. Buzdugan, P. Alarcon, B. Huntington, J. Rushton, D. P. Blake and J. Guitian, "Enhancing the Value of Meat Inspection Records for Broiler Health and Welfare Surveillance: Longitudinal Detection of Relational Patterns", BMC Veterinary Research, vol. 17, no. 278, August 2021.

[8] Tomasz Huscio and Roman Trochimczuk, "Novel Rope-Free Mechatronic Elevator System to Automation of Transport in Agricultural Farms", Proceedings of the 15th International Scientific Conference on Engineering for Rural Development, no. 15, pp. 318-323, May 2016.

[9] N. S. Amir, A. M. F. M. Abas, N. A. Azmi, Z. Z. Abidin and A. A. Shafie, "Chicken Farm Monitoring System", International Conference on Computer and Communication Engineering, pp. 132-137, July 2016.

[10] A. H. Abdullah, S. A. Shukor, F. S. A. Saad, P. Ehkan and H. Mustafa, "Wireless Electronic Nose using GPRS/GSM System for Chicken Barn Climate and Hazardous Volatile Compounds Monitoring and Control", 3rd International Conference on Electronic Design, pp.212-215, August 2016.

[11] Jake Astill, Rozita A. Dara, Evan D.G. Fraser, Bruce Roberts and Shayan Sharif, "Smart Poultry Management: Smart Sensors, Big Data, and the Internet of Things", Computers and Electronics in Agriculture, vol. 170, March 2020.

[12] A. Al-Nasser, H. Al-Khalaifah, H. Al-Mansour, A. Ahmad and G. Ragheb, "Evaluating Farm Size and Technology use in Poultry Production in Kuwait", World Poultry Science Journal, May 2020.

[13] Abhijeet Kumar, Prasanna Somerahally, Basavaraju Mahesh, Subhash Patlapati, Malathi V, Mahadevappa D Gouri, Jayanaik, Vivek M Patil, Jaya Nagappa Lakkundi, Ranjith Roy and Yadav Prabha Karan, "Comparative Study of Automation and Conventional System on Production 
Performance in Poultry Farms”, Journal of Animal Research, vol. 11, no. 1, pp. 187-197, February 2021.

[14] Cajethan Uche Ugwuoke, Felicia Ngozi Ezebuiro, Chinyere Roseline Okwo and Augustine Chukwuma Nnadi, "Management of Poultry Farms Through the Use of Electronic Facilities for Enhanced Food Security in Enugu State, Nigeria”, Global Journal of Biology, Agriculture and Health Science, vol. 6, no. 4, pp.1-7, October 2017.

[15] P. Jayarajan, M. Annamalai, V. A. Jannifer and A. A. Prakash, "IOT Based Automated Poultry Farm for Layer Chicken", 7th International Conference on Advanced Computing and Communication Systems, pp. 733-737, March 2021.

[16] Nikolaos Tzokas, Erik Jan Hultink and Susan Hart, "Navigating the New Product Development Process", Industrial Marketing Management, vol. 33, no. 7, pp. 619-626, October 2004.

[17] Kássio Santos, Eduardo Loures, Flávio Piechnicki and Osíris Canciglieri, “Opportunities Assessment of Product Development Process in Industry 4.0", Procedia Manufacturing, vol. 11, pp. 1358-1365, September 2017.

[18] Yuanbin Wang, Yuan Lin, Ray Y. Zhong and Xun Xu, "IoT Enabled Cloud-Based Additive Manufacturing Platform to Support Rapid Product Development", International Journal of Production Research, vol. 57, no. 12, August 2018.

[19] Muhammad Younas, Dayang Norhayati Abang Jawawi, Ahmad Kamil Mahmood, Mohammad Nazir Ahmad, Muhammad Umer Sarwar and Mohd Yazid Idris, "Agile Software Development Using Cloud Computing: A Case Study", IEEE Access, vol. 8, December 2019.

[20] Chao Shang, Fan Yang, Dexian Huang and Wenxiang Lyu, "Data-Driven Soft Sensor Development Based on Deep Learning Technique", vol. 24, no. 3, pp. 223-233, Journal of Process Control, March 2014.

[21] Chengwei Zhang, Youngwook Paul Kwon, Julia Kramer, Euiyoung Kim and Alice M. Agogino, "Deep Learning for Design in Concept Clustering", International Design Engineering Technical Conferences and Computers and Information in Engineering Conference, vol. 1, August 2017.

[22] Huafeng Quan, Shaobo Li and Jianjun Hu, "Product Innovation Design Based on Deep Learning and Kansei Engineering", Applied Sciences, vol. 8, no. 12, November 2018.

[23] Carmen Krahe, Antonio Bräunche, Alexander Jacob, Nicole Stricker and Gisela Lanza, "Deep Learning for Automated Product Design”, Procedia CIRP, vol. 91, pp. 3-8, 2020.

[24] Jilin Ye, Saurin Badiyani, Vinesh Raja and Thomas Schlegel, "Applications of Virtual Reality in Product Design Evaluation", Human-Computer Interaction: HCI Applications and Services, vol. 4553, pp. 1190-1199, 2007.

[25] Stig Ottosson, "Virtual reality in the Product Development Process", Journal of Engineering Design, vol. 13, no. 2, pp. 159-172, August 2002.

[26] R. K. J. De Silva, T. D. Rupasinghe and P. Apeagyei, "A Collaborative Apparel New Product Development Process Model Using Virtual Reality and Augmented Reality Technologies as Enablers", International Journal of Fashion Design, Technology and Education, vol. 12, no.1, April 2018.

[27] Sai Anirudh Karre, Neeraj Mathur and Y. Raghu Reddy, "Is Virtual Reality Product Development different?: An Empirical Study on VR Product Development Practices", Proceedings of the 12th Innovations on Software Engineering Conference, February 2019 no. 3, pp. 1-11, February 2019.

[28] Hans-Patrick Balzerkiewitz and Carsten Stechert, "Use of Virtual Reality in Product Development by Distributed Teams", Procedia CIRP, vol. 91, pp. 577-582, 2020.

[29] S. K. Ong, J. Zhang, Y. Shen and A. Y. C. Nee, "Augmented Reality in Product Development and Manufacturing", International Journal of Production Research, vol. 46, no. 10, pp. 2707-2742, March 2008

[30] Marcin Januszka and Wojciech Moczulski, "Acquisition and Knowledge Representation in the Product Development Process with the Use of Augmented Reality", Concurrent Engineering Approaches for Sustainable Product Development in a Multi-Disciplinary Environment, pp. 315326, 2013. 
[31] Dimitris Mourtzis, Vasilios Zogopoulos and Ekaterini Vlachou, "Augmented Reality Supported Product Design Towards Industry 4.0: A Teaching Factory Paradigm”, Procedia Manufacturing, vol. 23, pp. 207-212, 2018.

[32] H. M. Zulfabli, H. N. Ismalina, T. Amarul, and S. Ahmad, "Product Development of Mechanical Practice: Augmented Reality (AR) Approach", AIP Conference Proceedings, vol. 2129, July 2019.

[33] Dimitris Mourtzis, Vasilis Siatras, John Angelopoulos and Nikos Panopoulos, "An Augmented Reality Collaborative Product Design Cloud-Based Platform in the Context of Learning Factory", Procedia Manufacturing, vol. 45, pp. 546-55, April 2020.

[34] Pierre-Antoine Arrighi and Céline Mougenot, "Towards user Empowerment in Product Design: A Mixed Reality Tool for Interactive Virtual Prototyping", Journal of Intelligent Manufacturing, vol. 30, pp. 743-754, November 2016.

[35] Dmytro Adamenko, Robin Pluhnau and Arun Nagarajah, "Case Study of Model-Based Definition and Mixed Reality Implementation in Product Lifecycle", Design, Simulation, Manufacturing: The Innovation Exchange: Advances in Design, Simulation and Manufacturing II, pp. 3-12, June 2019.

[36] Young Mi Choi, "Utilization of Mixed Reality Tools in the Design of Wireless Assistive Products", Assistive Technology, June 2021.

[37] Lee Kent, Chris Snider and Ben Hicks, "Mixed Reality Prototyping: Synchronicity and its Impact on a Design Workflow", Proceedings of the Design Society, vol. 1, pp. 2117-2126, August 2021.

[38] Lee Kent, Chris Snider, James Gopsill and Ben Hicks, "Mixed Reality in Design Prototyping: A Systematic Review", Design Studies, vol. 77, Novermber 2021.

[39] Naheed Bashir, K.Nadia Papamichail, and Khaleel Malik, "Use of Social Media Applications for Supporting New Product Development Processes in Multinational Corporations", Technological Forecasting and Social Change, vol. 120, pp. 176-183, July 2017.

[40] Shugang Li, Yuqi Zhang, Yueming Li and Zhaoxu Yu, "The User Preference Identification for Product Improvement Based on Online Comment Patch", Electronic Commerce Research, vol. 21, pp. 423-444, August 2019.

[41] Khrystoforova, Viktoria and Siemieniako D, "Internet-Based Consumer Co-Creation Experience of the New Product Development Process", Engineering Management in Production and Services, vol. 11, no. 3, pp. 60-68, September 2019.

[42] Yixiong Feng, Yuliang Zhao, Hao Zheng, Zhiwu Li and Jianrong Tan, "Data-Driven Product Design Toward Intelligent Manufacturing: A Review", International Journal of Advanced Robotic Systems, vol. 17, no. 2, March 2020.

[43] Min Zhang, Brandon Fan, Ning Zhang, Wenjun Wang and Weiguo Fan, "Mining Product Innovation Ideas from Online Reviews", Information Processing \& Management, vol. 58, no. 1, January 2021.

[44] Jian Jin, Danping Jia and Kejia Chen, "Mining Online Reviews with a Kansei-Integrated Kano Model for Innovative Product Design", International Journal of Production Research, July 2021.

[45] HananYakubu and C.K.Kwong, "Forecasting the Importance of Product Attributes Using Online Customer Reviews and Google Trends", Technological Forecasting and Social Change, vol. 171, October 2021.

[46] Michael Spence, "Cost Reduction, Competition, and Industry Performance", The Econometric Society, vol. 52, no. 1, pp. 101-122, January 1984.

[47] Günther Schuh, Tim Wetterney and Florian Vogt, "Customer Need-based Product Positioning for Disruptive Innovations", Proceedings of the International Conference on Culture Heritage, Education, Sustainable Tourism, and Innovation Technologies, pp. 300-307, 2020.

[48] Amali Wijekoon, Sandeep Salunke and Gerard A. Athaide, "Customer Heterogeneity and Innovation-Based Competitive Strategy: A Review, Synthesis, and Research Agenda", vol. 38, no. 3, pp. 315-333, May 2021.

[49] PatrickWhitney, "Design and the Economy of Choice", She Ji: The Journal of Design, Economics, and Innovation, vol. 1, no. 1, pp. 58-80, 2015.

[50] Y. L. Tu, S. Q. Xie and Richard Y. K. Fung, "Product Development Cost Estimation in Mass Customization”, IEEE Transactions on Engineering Management, vol. 54, no. 1, pp. 29-40, January 2007. 
[51] Fredrik Hacklin and Martin W. Wallin, "Convergence and Interdisciplinarity in Innovation Management: A Review, Critique, and Future Directions”, The Service Industries Journal, vol. 33, no. 7, March 2013.

[52] Paul Gerber, Sönke Krebber, Ingmar Langer, Sinja Röbig, Susanne Sprenger And André Stocker, "Interdisciplinarity is a Key to Enhance the Product Development Process - How Students Deal with it and How They Evolve with it", International Conference on Engineering and Product Design Education, pp. 593-598, Spetember 2013.

[53] Figueiredo, João F., Nuno. Correia, Inês S. Ruivo and Jorge L. Alves, "Interdisciplinarity and Design Conceptualisation: Contributions from a Small-Scale Design Experiment”, Proceedings of the DMI 16 Conference, July 2016.

[54] Luiz Lagares Izidio, Bárbara de Oliveira Cruz, Rita Maria Couto, Luiza Novaes and Jackeline Lima Farbiarz "Design and Handicrafts: The Importance of Interdisciplinarity in Collaborative Design Practice", Strategic Design Research Journal, vol. 11, no. 1, pp. 9-14, January 2018.

[55] Marjorie Charrier, Florence Bazzaro and Jean-Claude Sagot, "Better Taking into Account People with Disabilities: Supporting the Interdisciplinarity Between Design and Ergonomics", Sciences du Design, vol. 8, no. 2, pp. 91-102, 2018.

[56] Vijayarajan Alagumalai, Pooja Kadambi and Abhishek Appaji, "Interdisciplinarity in New Product Development in an Indian MedTech Perspective: Gap and the Solution", Health and Technology, vol. 9, pp. 817-827, July 2019.

[57] Bárbara Rangel and Ângela Gomes, "Interdisciplinarity Between Design and Engineering Case Study: The Development of a Classroom Chair for Children Ages $6-10$ ", 2nd International Conference of the Portuguese Society for Engineering Education, October 2021.

[58] M. Bordegoni and G. Caruso, "Mixed Reality Distributed Platform for Collaborative Design Review of Automotive Interiors", Virtual and Physical Prototyping, vol. 7, no. 4, pp. 243-259, October 2012.

[59] Monica Bordegoni and Francesco Ferrise, "Designing Interaction with Consumer Products in a Multisensory Virtual Reality Environment", Virtual and Physical Prototyping, vol. 8, no. 1, pp. 5164, April 2013.

[60] Giorgio Colombo, Giancarlo Facoetti, Daniele Regazzoni and Caterina Rizzi, "A Full Virtual Approach to Design and Test Lower Limb Prosthesis", Virtual and Physical Prototyping, vol. 8, no. 2, pp , 97-111, July 2013.

[61] Tarja Tiainen, Asko Ellman and Taina Kaapu, "Virtual Prototypes Reveal More Development Ideas: Comparison Between Customers' Evaluation of Virtual and Physical Prototypes", Virtual and Physical Prototyping, vol. 9, no. 3, pp. 169-180, July 2014.

[62] SusannaAromaaa and KaisaVäänänenb, "Suitability of Virtual Prototypes to Support Human Factors/Ergonomics Evaluation During the Design", Applied Ergonomics, vol. 56, pp. 11-18, September 2016.

[63] Mark P. Mobach, "Virtual Prototyping to Design Better Corporate Buildings", Virtual and Physical Prototyping, vol. 5, no. 3, pp. 163-170, 2010. 